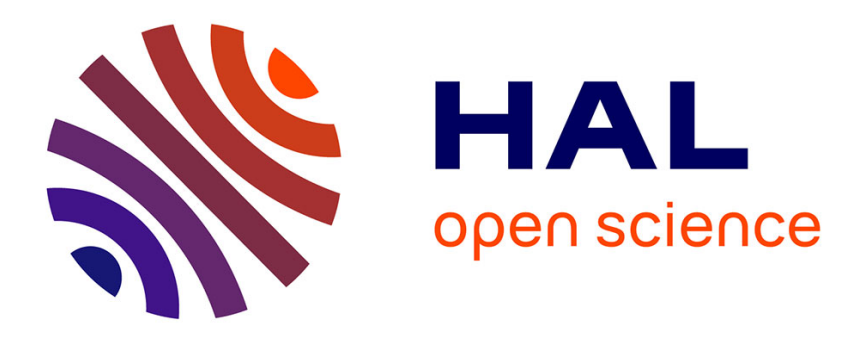

\title{
Improving Health Status through Physical Activity for Individuals with Chronic Pulmonary Diseases
}

\author{
Alain Varray
}

\section{To cite this version:}

Alain Varray. Improving Health Status through Physical Activity for Individuals with Chronic Pulmonary Diseases. Adapted Physical Activity Quarterly, 2006, 23 (2), pp.111-128. 10.1123/apaq.23.2.111 . hal-01622434

\section{HAL Id: hal-01622434 \\ https://hal.umontpellier.fr/hal-01622434}

Submitted on 25 Oct 2017

HAL is a multi-disciplinary open access archive for the deposit and dissemination of scientific research documents, whether they are published or not. The documents may come from teaching and research institutions in France or abroad, or from public or private research centers.
L'archive ouverte pluridisciplinaire HAL, est destinée au dépôt et à la diffusion de documents scientifiques de niveau recherche, publiés ou non, émanant des établissements d'enseignement et de recherche français ou étrangers, des laboratoires publics ou privés. 
Page header: Physical Activity, Chronic Respiratory Disease and Health

Fourth G. Lawrence Rarick Memorial Lecture

$$
15^{\text {th }} \text { ISAPA - Verona. }
$$

Improving Health Status Through Physical Activity for Individuals with Chronic Pulmonary Diseases: Theory to Practice.

\author{
Alain Varray \\ Laboratory EUROMOV \\ University of Montpellier \\ 700 avenue du Pic Saint Loup \\ F-34090 Montpellier - France \\ Phone: (+33) 434432646 \\ Mail: alain.varray@umontpellier.fr
}




\begin{abstract}
The aim of this paper is to show how pertinent pathophysiological bases have been built for physical activity prescription for individuals with obstructive pulmonary disease (asthma and chronic obstructive pulmonary disease). The pathophysiological bases were constructed by taking into account exercise mismatching, which was analysed in terms of both short- and long-term impact on disease outcome. Specific exercise adaptations based on a keen understanding of the underlying physiological processes provided the key to an adapted intervention with well-defined exercise program aims. The results that were achieved are striking, and one might conclude that sometimes exercise is simply the best way to improve the general well-being of individuals with chronic disease. Since this is a major concern for health professionals and chronically ill individuals, physical activity offers a means to rise to this challenge.
\end{abstract}


The interaction between exercise and health is now evident, and the amount of scientific information amassed on this topic is considerable. We have numerous examples in the literature of regular exercise being a powerful means to counter functional deterioration due to sedentary living. Most of the time, this concept is applied to healthy individuals, but the issue becomes much more complicated when exercise is proposed for individuals with chronic disease, especially when the disease implies a sharp reduction in exercise tolerance. The use of physical activity in chronic disease states is quite recent. Originally, the intention was to disprove the long-held conviction that physical activity is contraindicated in chronic disease states. This first step was essentially driven by a humanistic concern and we owe much to the work of several pioneers (Bar-Or, 1985; Shephard, 1982, 1884). We are currently undergoing a tremendous shift in thinking, and exercise prescription is increasingly viewed as an efficient means to manage disease. This change is truly surprising because, in cases of chronic disease states, physical activity is never intuitively accepted.

Bar-Or (1985) was one of the first scientists to model the dynamic between a chronic disease state and subsequent functional deterioration (Figure 1). With chronic illness, the habitual level of activity is often decreased and the resulting deconditioning reinforces hypoactivity. For a long time, this vicious circle of hypoactivity was only considered as deleterious for "normal" individuals. Today, however, we have indisputable evidence of the aggravating consequences of hypoactivity on the disease process itself. We thus might logically assume that acceptance of physical activity is a given. Unfortunately, however, this is not the case because in chronic disease states, a strange paradox occurs: From a longterm perspective, the positive effects of physical activity have been supported by a number of studies (ACCP AACVPR Pulmonary Rehabilitation Guidelines Panel, 1997; Bak, Jacobsen, Jorgensen, \& Pedersen, 1989; Varray \& Prefaut, 1992) but because of short-term fears experienced by the patients during exercise, physical activity will often be avoided and the long-term effects are thus never attained (see some typical examples in Table 1). The main challenge today is therefore to determine how this paradox can be resolved. In our experience, a powerful solution is suggested by a careful response to the following questions:

- why should exercise training be proposed? In other words, we need to know the specific goals to be achieved in a very precise pathology; 
Physical Activity, Chronic Disease and Health

- how should training be carried out? The procedural problems are always delicate and must be dealt with according to the stated aims defined for the specific pathology and the classical effects of training;

- what type of results can be expected by training? Again, it is impossible to give a relevant answer without a clear definition of the training goals.

We ask these three questions because experience has taught us that we cannot consider implementing any physical activity program without first defining its pathophysiological bases. These bases must be built from precise knowledge of the physiological exercise impairments encountered in specific pathological states, and by a thorough analysis of their short- or long-term consequences for the individuals.

Thus, the aim of this paper is to examine the issues that have limited the acceptance of physical activity by drawing on our experience with children and adults with pulmonary diseases. The second aim is to demonstrate how improved knowledge of exercise adaptations has resulted in some specific justifications for physical activity and a more relevant understanding of final activity aims. Last, we will present how applied research has provided data showing the efficacy of physical activity adapted to individuals with respiratory illness.

\section{Bronchial asthma: from exercise adaptations to pathophysiological justification of exercise training}

Asthma is defined as a "clinical syndrome characterized by reversible obstruction to airflow and increased bronchial responsiveness to a variety of stimuli both allergic and environmental" (Mannino, Homa, Akinbami, Ford, \& Redd, 2002). Asthma is a very common disease and, unfortunately, despite improvements in disease management, its prevalence and severity are rising in industrial countries (Basagana et al., 2004; Rees, 2005). Consistent with its definition, asthma is characterized by an abnormal bronchial responsiveness to various stimuli, among them exercise. For many years, exercise was contraindicated because of a particular manifestation of the disease called exercise-induced asthma (EIA). The typical expression of EIA is a drop in respiratory function, which can be maximal within the first 15 minutes following intense exercise, and during which the subject wheezes and feels dyspnea. For many years, EIA was considered as an exacerbation of asthma directly attributed to 
Physical Activity, Chronic Disease and Health exercise. The studies on EIA led to two major findings: 1) EIA is not due to exercise but to hyperventilation (Bundgaard, Ingemann-Hansen, Schmidt, \& Halkjaer-Kristensen, 1981) and 2) the pathophysiological pathways of EIA are not the same as in a classical asthma attack since bronchial hyperosmolarity is still considered to be mainly implicated (Anderson \& Daviskas, 2000). As a consequence, the name "exercise-induced bronchospasm" (EIB) is now preferred because of its higher pathophysiological relevance. The link between exercise hyperventilation and physical fitness is so important that we must first fully understand the exercise cardiorespiratory adaptations in terms of exercise tolerance, sensitivity to EIB, and the role played by asthma severity in the adjustment to exercise, in order to conclude on the relevant pathophysiological bases for APA in asthma. Today, despite some controversy in the literature due to a lack of direct control groups, we have evidence that both anaerobic (Counil et al., 2001; Counil et al., 1997) and aerobic fitness (Clark \& Cochrane, 1988; Freeman, Nute, \& Williams, 1989; Varray, Mercier, Savy-Pacaux, \& Prefaut, 1993) are appreciably lower in individuals with asthma. From a pathophysiological point of view, the decreased aerobic fitness is troublesome. Moreover, hypoactivity cannot entirely explain these differences in comparison with normal populations, since in some studies the asthmatics were normally active. In contrast, we have shown that altered aerobic fitness is linked to the degree of airway obstruction (Varray, Mercier, Ramonatxo, \& Prefaut, 1989) and is mainly explained by low cardiac output (Varray et al., 1993). The consequences of these limitations must be taken into account because low aerobic fitness in childhood can have a deep impact on functional capacity and the risk of an abnormally sedentary lifestyle is high. In asthmatic individuals, this risk is reinforced because of the breathlessness experienced during exercise, which leads naturally to negative attitudes toward exercise.

Another exercise misadaptation in asthmatics is an obvious excessive hyperventilation for a given workload (Chryssanthopoulos, Maksud, Funahashi, Hoffmann, \& Barboriak, 1979). With our improved understanding of EIB pathophysiology, we now know that any increase in minute ventilation is a potent stimulus to EIB, whatever the exact nature of the underlying mechanism [Hyperosmolarity due to respiratory water loss (Sheppard \& Eschenbacher, 1984) or associated vascular events (Ichinose et al., 1996; McFadden, 1990)]. Fortunately, asthmatics can reduce this risk by a specific exercise adaptation: exercise-induced bronchodilation (Haas et al., 1987; Haas, Pineda, Axen, Gaudino, \& Haas, 1985), which can reach $30 \%$ of pre-exercise values. The only problem is that 
Physical Activity, Chronic Disease and Health this "protective" reaction occurs only if aerobic fitness is good enough. Thus, the need to improve physical fitness is all the more important, and the presence of EIB can no longer be used to justify the avoidance of physical activity. Indeed, with a sedentary lifestyle, aerobic fitness will progressively decrease and the exercise bronchodilation will disappear, resulting in an even lower exercise tolerance with regard to EIB.

A less well known result is that hyperventilation is linked to decreased cardiac output due to heartlung interactions. Indeed, a strong relationship has been obtained between submaximal stroke volume and level of hyperventilation during an incremental exercise in asthmatics (Varray et al., 1993). This phenomenon can be explained by abnormal end expiratory lung volume with important consequences for cardiac efficiency (Babb, Viggiano, Hurley, Staats, \& Rodarte, 1991; Varray et al., 1993). Again, the negative impact of hyperventilation levels must be underlined in addition to the previous effects on EIB risk.

In summary, the main hurdle to exercise in asthmatics is always EIB, especially when asthma is severe. However, an understanding of the specific asthmatic exercise adaptations provides convincing arguments for the use of exercise training as a means to improve patients' well-being and quality of life. By understanding these adaptations, appropriate pathophysiological aims for adapted physical activity can be defined, as these aims are very closely based on the concrete impairments encountered in asthma. The first aim is to improve aerobic fitness, because this is a very powerful means to counter the functional deterioration that leads to an inactive lifestyle and its subsequent problems, and to improve the exercise bronchodilation in order to reduce EIB risk. The second and probably the more important goal is to reduce excessive hyperventilation to reduce: 1) the unpleasant feeling of breathlessness during exercise that is at the root of the negative attitudes toward exercise, 2) the potent risk of EIB, and 3) the cardiovascular alteration mediated by excessive ventilation requirement. Last, because asthma severity plays an important role in impaired exercise adaptation, the physical activity intensities must be carefully individualized to the true exercise capacity of each asthmatic (Varray \& Prefaut, 1992). This is the only way to ensure efficient training procedures and to reach the above pathophysiological goals. 
Physical Activity, Chronic Disease and Health

COPD is defined as a "preventable and treatable disease state characterised by airflow limitation that is not fully reversible. The airflow limitation is usually progressive and is associated with an abnormal inflammatory response of the lungs to noxious particles or gases, primarily caused by cigarette smoking" (Celli \& MacNee, 2004, p. 933). COPD is a leading cause of morbidity and mortality worldwide, and the social and economic burden is both substantial and increasing. Despite a systematic underestimation (the disease is difficult to identify until it becomes clinically apparent), COPD is increasingly prevalent and fatal (Mannino et al., 2002). Two studies project that mortality due to COPD will rise from $6^{\text {th }}$ place in 1990 to $3^{\text {rd }}$ place in 2020 (Murray \& Lopez, 1997; Stang, Lydick, Silberman, Kempel, \& Keating, 2000). From a clinical point of view, COPD is characterized by a progressive and permanent airflow limitation due to bronchial obstruction. At the last stage of the disease, respiratory failure can occur, which then requires long-term oxygen therapy. The major symptom of the disease is dyspnea, which can be experienced during any daily activity (walking, getting dressed, eating, and so on). The obvious consequences will be a sharp drop in the quality of life and poor social interactions (Scharloo, Kaptein, Weinman, Willems, \& Rooijmans, 2000), abnormal levels of depression (Kunik et al., 2005; Mikkelsen, Middelboe, Pisinger, \& Stage, 2004; Wagena, Arrindell, Wouters, \& can Schayck, 2005), and a clear exercise intolerance (Carter, Holiday, Stocks, \& Teip, 2003; Oga et al., 2005; Prefaut, Varray, \& Vallet, 1995). Originally, physical training for individuals with COPD was thought to be without justification for two main reasons. The first was directly linked to the presence of dyspnea even in resting conditions: any exercise was assumed to be detrimental because of dyspnea worsening. The second was more closely related to the fact that COPD is an obstructive disease: it was widely believed (no longer the case) that the only way to improve patients was to increase lung function, which is not possible with exercise training. Thus, exercise training was considered to be really difficult to manage or even absolutely irrelevant.

Fortunately, over the past ten years, the many studies on the COPD/exercise interface have completely modified our concept of the disease. Among the major changes, COPD is no longer considered an isolated respiratory disease, but as a systemic disease with the lung as a starting point. The systemic repercussions of the disease have thus been increasingly studied (Agusti et al., 2003), and it now seems evident that exercise tolerance is not directly linked to the severity of bronchial obstruction, but is mainly affected by peripheral factors, among which muscle function plays a central 
Physical Activity, Chronic Disease and Health

role. For example, it is well known that muscle dysfunction occurs during exercise even without a problem in oxygen supply (Gosselin et al., 2003; Maltais et al., 1998; Maltais et al., 2001; Simon et al., 2001). The implication of muscle function in COPD exercise tolerance, quality of life and survival rates is probably one of the most striking discoveries of the research into the disease and its management. The data are quite recent, and their importance is well summarized by the amazing title of one editorial published in a leading review in the field: "COPD as a muscle disease" (Reid, 2001). As a consequence, the focus on the unique link between lung function and exercise tolerance has become irrelevant. On the contrary, if dyspnea can be related to impaired muscle function, exercise training becomes a powerful tool for decreasing exercise dyspnea because of its known effect on the ventilatory requirement. The major challenge of the last few years has thus been to prove that muscle function abnormalities can be responsible for excessive dyspnea.

COPD muscle presents both quantitative and qualitative abnormalities. The muscle mass is sharply reduced (Baarends et al., 1997). The fiber typology is also modified in comparison with that of nonCOPD individuals, with an important reduction in oxidative fibers (type I) and an increased proportion of fast fatiguing glycolytic fibers (type IIb) (Whittom et al., 1998). The enzymatic equipment is characterized by the decreased activity of several oxidative enzymes such as citrate synthetase, 3-hydroxyacyl CoA dehydrogenase (Maltais et al., 1996) and the preserved activity of glycolytic enzymes like lactate dehydrogenase (LDH) and phosphofructokinase (PFK). Because of the above, several consequences are easy to understand: maximal force will be decreased (Gosselink, Troosters, \& Decramer, 1996), as will muscle endurance, even in localized exercise - that is, even without reaching the subject's ventilatory limits (Serres, Gautier, Varray, \& Prefaut, 1998). Cardiorespiratory fitness is sharply reduced (Serres et al., 1998; Vallet, Varray, Fontaine, \& Prefaut, 1994) and significant muscle dysfunction occurs during the onset of incremental exercise characterized by a drop in muscle excitability (Gosselin et al., 2003). More qualitatively, excessive anaerobic contribution is exhibited by COPD patients from the beginning of any general (Maltais et al., 1998) or localized exercise (Wuyam et al., 1992). It is worth noting that in both types of exercise, this anaerobic contribution occurs prior to any impairment in the muscle oxygen supply. Because of an excessive anaerobic contribution for a given exercise intensity, lactic acid production will lead to excessive $\mathrm{H}^{+}$concentration in the muscle and then in the blood. The intervention of the buffering 
Physical Activity, Chronic Disease and Health system ( $\left.\mathrm{NaHCO}^{-}\right)$will rapidly produce excessive $\mathrm{CO}_{2}$. A short time later, when the buffering system is exceeded, metabolic acidosis occurs (Maltais et al., 1998). Both $\mathrm{CO}_{2}$ production and acidosis (via carotid body stimulation) are potent stimuli of respiratory centers. These findings describe the direct link between muscle dysfunction and dyspnea, despite the apparent independence between respiratory impairment and muscle structure, since excessive hyperventilation for a given exercise intensity will increase dyspnea in COPD. In addition, an understanding of the metabolic pathways provides insight into why dyspnea may progressively increase, even with stable disease, because of deconditioning effects on muscle function. This has been described by the concept of the dyspnea spiral [see Figure 2 (Prefaut et al., 1995)], which assumes that dyspnea in COPD is first experienced at maximal exercise intensity. As a consequence, spontaneous activity will be decreased to avoid any situation in which dyspnea might reoccur. The deconditioning effects will be a decreased aerobic participation in ATP synthesis during exercise, counteracted by increased anaerobic involvement. The respiratory centers will be more stimulated by extra $\mathrm{CO}_{2}$ production and/or acidosis and the dyspnea will increasingly be felt for lower exercise intensities, independently of any disease worsening. The same causes will produce comparable effects, and daily physical activity will progressively be reduced, with worsening effects on muscle function and anaerobic metabolism contribution for a given exercise level, and exacerbation of dyspnea for lower and lower exercise intensities. Thus, dyspnea is no longer considered as a unique manifestation of the respiratory impairment due to COPD, but is instead seen as an interface between the prime pathology (bronchial obstruction) and a true secondary pathology typified by muscle dysfunction. The use of exercise training is thus more relevant than it was thought to be in the past. Moreover, this insight into the relationship between muscle dysfunction and dyspnea is an illustration of one of the pathophysiological bases for retraining programs in COPD: we need to improve muscle function, and especially its aerobic capacity, to be able to lower ventilatory center drive and thus to reduce dyspnea by decreased anaerobic contribution for any given exercise level, even if the severity of the pathology remains (unfortunately) unchanged. The impact of these bases is tremendous, because they provide a striking opportunity to combat the major symptom of the disease. Thanks to physical activity prescription based on solid pathophysiological understanding, hope of an improved quality of life can now be offered to individuals with chronic illnesses. 
Physical Activity, Chronic Disease and Health

It is important to note that the exact factors that cause skeletal muscle dysfunction in COPD are for the most part unknown. Although it seems evident that a sedentary lifestyle plays an important role (Goris, Vermeeren, Wouters, Schols, \& Weserterp, 2003; Pitta et al., 2005), there are several reasons to think that inactivity, albeit an important element, is not the only factor responsible for this dysfunction, especially the finding that training programs fail to totally normalize this dysfunction (Troosters, Casaburi, Gooselink, \& Decramer, 2005). Several studies have provided strong arguments in favor of systemic inflammation as a mechanism for the development of muscle weakness and muscle apoptosis (Debigare et al., 2003; Spruit et al., 2003). Recently, muscle oxidative stress was described during rest and exercise in COPD (Heunks et al., 1999), even during localized exercise (Couillard, Keochlin, Cristol, Varray, \& Prefaut, 2002; Couillard et al., 2003). The consequences of oxidative stress on lipid membrane and proteins are numerous and are strongly implicated in exercise intolerance (Koechlin et al., 2004). Another potential factor is related to the angiotensin-converting enzyme genotype in COPD, which would explain the large difference in quadriceps force (Hopkinson et al., 2004) and endurance (Gosker, Pennings, \& Schols, 2004) in COPD individuals. Irrespective of the exact underlying mechanisms that lead to muscle alterations, the above pathophysiological bases are relevant because the adapted training programs aim to reverse skeletal muscle dysfunction and its consequences on dyspnea and exercise intolerance.

As for asthmatics, the individualization of retraining intensities is of prime importance to ensure that excessive dyspnea feelings are prevented and that exercise will thus be well tolerated. To avoid this problem, we chose to promote and validate a training intensity at the ventilatory threshold [VTh, (Beaver, Wasserman, \& Whipp, 1986)] since it represents an individual parameter of cardiorespiratory fitness and characterizes the maximal exercise intensity prior to an exponential rise in ventilation (Figure 3) that is an efficient intensity without causing major dyspnea feelings (Varray \& Prefaut, 1995).

\section{The effects of retraining programs on individuals with obstructive pulmonary disease}

As we have seen above, and even if the underlying reasons are quite different in asthma and COPD, the major aim of training programs is to counter the excessive ventilation requirement by developing greater aerobic fitness. This aim is based on precise pathophysiological analysis. Because this 
Physical Activity, Chronic Disease and Health objective and the efficacy of training effects are similar in asthmatics and COPD patients, we will present the effects of physical activity in both patient groups in the same part.

Although few general reviews have been published on the overall effects of physical activity in asthmatics (Ram, Robinson, Black, Picot, \& Ram, 2005; Welsh, Kemp, \& Roberts, 2005), the impact on different asthma symptoms or their consequences have long been known and confirmed in more recent studies. The main consequences are fewer and less severe asthmatic attacks (Petersen \& McElhenney, 1965), fewer wheezing days, fewer days requiring medication, and decreased hospitalizations and school absenteeism (Huang, Veiga, Sila, Reed, \& Hines, 1989; Szentagothai, Gyene, Szocska, \& Osvath, 1987; Wardell \& Isbister, 2000). The effects on EIB risk remain debatable, since some studies have described a decrease in the frequency and degree of EIB after training, and others have not (Welsh et al., 2005). The underlying reasons for the discrepancies are probably differences in training regimen, as the reduction in EIB is strongly supported by cardiorespiratory effects (presented further).

In contrast, the amount of work carried out on the training effects on COPD is so great that several reviews, meta-analyses and publications on "evidence-based medicine" have been published (ACCP AACVPR Pulmonary Rehabilitation Guidelines Panel, 1997; BTS Statement, 2001; Chavannes, Vollenberg, van Schayck, \& Wouters, 2002; Lacasse et al., 2003; Lacasse et al., 1996; Troosters et al., 2005). The literature devoted to evidence-based medicine rates the strength of evidence according to three different levels:

- grade A: evidence from well designed, well conducted, controlled trials with statistically significant results. This grade is the highest and characterizes the proven efficacy of a treatment;

- grade B: evidence from observational studies or controlled trials with less consistent results. This grade indicates that a technique is efficient but acknowledges a remaining lack of certainty;

- grade C: expert opinion supports the guideline recommendations though the available research does not have consistent results and controlled trials are lacking.

According to this classification, pulmonary rehabilitation based on retraining programs is currently the only technique accorded a grade A for its effectiveness in improving the breathlessness, 
Physical Activity, Chronic Disease and Health

depression and anxiety associated with COPD; the number and duration of hospitalizations; the health-related quality of life; and — to an amazing degree — the exercise tolerance (that is, increased exercise capacity and decreased breathlessness for any given exercise intensity (ACCP AACVPR Pulmonary Rehabilitation Guidelines Panel, 1997; Fabbri \& Hurd, 2003). In addition, pulmonary rehabilitation has received a grade B for improved survival rate

Among these general effects, the central one is obviously the substantial increase in exercise tolerance, which is the exact response expected from a training program built on pathophysiological bases. By using individualized training programs, it is possible to induce better aerobic fitness $\left(\dot{\mathrm{VO}}_{2} \max\right.$ and VTh) in asthmatics (Ahmaidi, Varray, Savy-Pacaux, \& Prefaut, 1993; Varray, Mercier, Terral, \& Prefaut, 1991) and patients with COPD, although with a lower magnitude in this population (Vallet et al., 1994). The improvement in VTh means that the ventilatory requirement is lowered at submaximal intensities, since the moment of an exponential increase in ventilation is delayed. In addition, several studies have shown ventilatory savings in asthmatics for any exercise intensity (Hallstrand, Bates, \& Schoene, 2000; Varray, Mercier, \& Prefaut, 1995) and in COPD patients for heavy exercise workloads (Vallet et al., 1997). As mentioned in the pathophysiological section, these results are of prime importance, since the dyspnea will be reduced for any given exercise intensity and thus the dyspnea feeling is lessened. More specifically, in asthmatics, this represents a decreased risk of EIB and the possibility of reduced heart-lung interactions. Another very interesting finding is that after training, the breathing pattern is modified with a systematic decrease in breathing frequency for a given ventilation level in both populations. This means that alveolar ventilation will be higher for a given ventilatory flow, reflecting a decrease in dynamic hyperinflation in asthmatics (Ramazanoglu \& Kraemer, 1985) and COPD patients (Porszasz et al., 2005). Thus by changing the breathing pattern, the main ventilatory effects are maximized.

Because of a strong muscle dysfunction in COPD, the literature reports several attempts to provide evidence that skeletal muscle may be more efficient during exercise. By using the model of localized exercise, it has been shown that training can induce important changes in muscle function, and especially higher critical power, which means that more intense exercise can be performed without fatigue (Serres, Varray, Vallet, Micallef, \& Prefaut, 1997). In addition, quadriceps endurance after 
Physical Activity, Chronic Disease and Health

training can be increased up to $250 \%$ of its pre-training value. The muscle impairment characterized by an early drop in muscle excitability can also be corrected by individualized training [Figure 4 (Gosselin, et al., 2003)].

More recently, decreased oxidative stress was described after training (Mercken et al., 2005), especially training in submaximal exercise conditions. The underlying mechanisms are unclear, and it is still unknown whether this decrease is attributable to a more efficient oxidative metabolism or an increased capacity of endogenous antioxidative systems. 


\section{Conclusion}

Because of the effectiveness of retraining programs that have been developed from pathophysiological bases, the overall quality of life of individuals with obstructions can be sharply improved. This is illustrated by better functional status despite the chronicity of the disease. However, it is important to bear in mind that training is not always efficient and close monitoring of physical activity is essential. Indeed, one comparative work showed that with the use of non-individualized intensities - that is, standardized intensities for all individuals - the training program failed to decrease the ventilation or the anaerobic requirement, as was expected [Figure 5 (Vallet et al., 1997)]. This indicates that 1) physical activity prescription requires an attentive and knowledgeable approach, 2) the professional expertise of physical education teachers specializing in adapted physical activity is indispensable, and 3) training intensities must be defined by taking into account the triad of "pathology-exercise adaptations-training effects".

Last but not least, since functional improvement is always possible irrespective of the disease severity (Vogiatzis, Williamson, Miles, \& Taylor, 1999), hope can now be offered to individuals with chronic diseases: a better quality of life starting today. 
Physical Activity, Chronic Disease and Health

\section{References}

ACCP AACVPR Pulmonary Rehabilitation Guidelines Panel. (1997). Pulmonary rehabilitation: joint ACCP/AACVPR evidence-based guidelines. Chest, 112, 1363-1396.

Agusti, A. G., Noguera, A., Sauleda, J., Sala, E., Pons, J., \& Busquets, X. (2003). Systemic effects of chronic obstructive pulmonary disease. European Respiratory Journal, 21, 347360.

Ahmaidi, S. B., Varray, A. L., Savy-Pacaux, A. M., \& Prefaut, C. G. (1993). Cardiorespiratory fitness evaluation by the shuttle test in asthmatic subjects during aerobic training. Chest, 103, 1135-1141.

Anderson, S. D., \& Daviskas, E. (2000). The mechanism of exercise-induced asthma is. Journal of Allergy and Clinical Immunology, 106, 453-459.

ATS official statement. (1987). Standards for the diagnosis and care of patients with chronic obstructive pulmonary disease (COPD) and asthma. American Review of Respiratory Disease, 136, 225-244.

Baarends, E. M., Schols, A. M., Mostert, R., \& Wouters, E. F. (1997). Peak exercise response in relation to tissue depletion in patients with chronic obstructive pulmonary disease. European Respiratory Journal, 10, 2807-2813.

Babb, T. G., Viggiano, R., Hurley, B., Staats, B., \& Rodarte, J. R. (1991). Effect of mild-tomoderate airflow limitation on exercise capacity. Journal of Applied Physiology, 70, 223230.

Bak, J. F., Jacobsen, U. K., Jorgensen, F. S., \& Pedersen, O. (1989). Insulin receptor function and glycogen synthase activity in skeletal muscle biopsies from patients with insulindependent diabetes mellitus: effects of physical training. Journal of Clinical Endocrinology and Metabolism, 69, 158-164.

Bar-Or, O. (1985). Pediatric Sports Medicine for the Practitioner. New-York: Springer.

Basagana, X. et al. (2004). Socioeconomic status and asthma prevalence in young adults: the European Community Respiratory Health Survey. American Journal of Epidemiology, 160, 178-188.

Beaver, W. L., Wasserman, K., \& Whipp, B. J. (1986). A new method for detecting anaerobic threshold by gas exchange. Journal of Applied Physiology, 60, 2020-2027.

BTS Statement. (2001). Pulmonary rehabilitation. Thorax, 56, 827-834.

Bundgaard, A., Ingemann-Hansen, T., Schmidt, A., \& Halkjaer-Kristensen, J. (1981). The importance of ventilation in exercise-induced asthma. Allergy, 36, 385-389. 
Physical Activity, Chronic Disease and Health

Carter, R., Holiday, D. B., Stocks, J., \& Tiep, B. (2003). Peak physiologic responses to arm and leg ergometry in male and female patients with airflow obstruction. Chest, 124, 511518.

Celli, B. R., \& MacNee, W. (2004). Standards for the diagnosis and treatment of patients with COPD: a summary of the ATS/ERS position paper. European Respiratory Journal, 23, 932-946.

Chavannes, N., Vollenberg, J. J., van Schayck, C. P., \& Wouters, E. F. (2002). Effects of physical activity in mild to moderate COPD: a systematic review. British Journal of General Practice, 52, 574-578.

Chryssanthopoulos, C., Maksud, M. G., Funahashi, A., Hoffmann, R. G., \& Barboriak, J. J. (1979). An assessment of cardiorespiratory adjustments of asthmatic adults to exercise. Journal of Allergy and Clinical Immunology, 63, 321-327.

Clark, C. J., \& Cochrane, L. M. (1988). Assessment of work performance in asthma for determination of cardiorespiratory fitness and training capacity. Thorax, 43, 745-749.

Couillard, A., Koechlin, C., Cristol, J. P., Varray, A., \& Prefaut, C. (2002). Evidence of local exercise-induced systemic oxidative stress in chronic obstructive pulmonary disease patients. European Respiratory Journal, 20, 1123-1129.

Couillard, A. et al. (2003). Exercise-induced quadriceps oxidative stress and peripheral muscle dysfunction in patients with chronic obstructive pulmonary disease. American Journal of Respiratory and Critical Care Medicine, 167, 1664-1669.

Counil, F. P. et al. (2001). Anaerobic fitness in children with asthma: adaptation to maximal intermittent short exercise. Pediatric Pulmonology, 31, 198-204.

Counil, F. P.et al. (1997). Wingate test performance in children with asthma: aerobic or anaerobic limitation? Medicine and Science in Sports \& Exercise, 29, 430-435.

Debigare, R. et al. (2003). Catabolic/anabolic balance and muscle wasting in patients with COPD. Chest, 124, 83-89.

Fabbri, L. M., \& Hurd, S. S. (2003). Global Strategy for the Diagnosis, Management and Prevention of COPD: 2003 update. European Respiratory Journal, 22, 1-2.

Freeman, W., Nute, M. G., \& Williams, C. (1989). The effect of endurance running training on asthmatic adults. British Journal of Sports Medicine, 23, 115-122.

Goris, A. H., Vermeeren, M. A., Wouters, E. F., Schols, A. M., \& Westerterp, K. R. (2003). Energy balance in depleted ambulatory patients with chronic obstructive pulmonary 
Physical Activity, Chronic Disease and Health disease: the effect of physical activity and oral nutritional supplementation. British Journal of Nutrition, 89, 725-731.

Gosker, H. R., Pennings, H. J., \& Schols, A. M. (2004). ACE Gene Polymorphism in COPD. American Journal of Respiratory and Critical Care Medicine, 170, 572; author reply 572573.

Gosselin, N. et al. (2003). Endurance training improves skeletal muscle electrical activity in active COPD patients. Muscle Nerve, 28, 744-753.

Gosselin, N. et al. (2003). Electrophysiologic changes during exercise testing in patients with chronic obstructive pulmonary disease. Muscle Nerve, 27, 170-179.

Gosselink, R., Troosters, T., \& Decramer, M. (1996). Peripheral muscle weakness contributes to exercise limitation in COPD. American Journal of Respiratory and Critical Care Medicine, 153, 976-980.

Haas, F. et al. (1987). Effect of aerobic training on forced expiratory airflow in exercising asthmatic humans. Journal of Applied Physiology, 63, 1230-1235.

Haas, F., Pineda, H., Axen, K., Gaudino, D., \& Haas, A. (1985). Effects of physical fitness on expiratory airflow in exercising asthmatic people. Medicine and Science in Sports \& Exercise, 17, 585-592.

Hallstrand, T., Bates, P., \& Schoene, R. (2000). Aerobic conditioning in mild asthma decreases the hyperpnea of exercise and improves exercise and ventilatory capacity. Chest, $118,1460-1469$.

Heunks, L. M. et al. (1999). Xanthine oxidase is involved in exercise-induced oxidative stress in chronic obstructive pulmonary disease. American Journal of Physiology, 277(6 Pt 2), R1697-1704.

Hopkinson, N. S. et al. (2004). Angiotensin converting enzyme genotype and strength in chronic obstructive pulmonary disease. American Journal of Respiratory and Critical Care Medicine, 170, 395-399.

Huang, S. W., Veiga, R., Sila, U., Reed, E., \& Hines, S. (1989). The effect of swimming in asthmatic children--participants in a swimming program in the city of Baltimore. Journal of Asthma, 26, 117-121.

Ichinose, M. et al. (1996). A neurokinin 1-receptor antagonist improves exercise-induced airway narrowing in asthmatic patients. American Journal of Respiratory and Critical Care Medicine, 153, 936-941. 
Physical Activity, Chronic Disease and Health

Koechlin, C. et al. (2004). Does oxidative stress alter quadriceps endurance in chronic obstructive pulmonary disease? American Journal of Respiratory and Critical Care Medicine, 169, 1022-1027.

Kunik, M. E. et al. (2005). Surprisingly high prevalence of anxiety and depression in chronic breathing disorders. Chest, 127, 1205-1211.

Lacasse, Y. et al. (2003). Pulmonary rehabilitation for chronic obstructive pulmonary disease (Cochrane Review). The Cochrane Library (2), Oxford: Update Software.

Lacasse, Y. et al. (1996). Meta-analysis of respiratory rehabilitation in chronic obstructive pulmonary disease. Lancet, 348, 1115-1119.

Maltais, F. et al. (1998). Metabolic and hemodynamic responses of lower limb during exercise in patients with COPD. Journal of Applied Physiology, 84, 1573-1580.

Maltais, F. et al. (1996). Oxidative capacity of the skeletal muscle and lactic acid kinetics during exercise in normal subjects and in patients with COPD. American Journal of Respiratory and Critical Care Medicine, 153, 288-293.

Maltais, F. et al. (2001). Effects of oxygen on lower limb blood flow and O2 uptake during exercise in COPD. Medicine and Science in Sports \& Exercise, 33, 916-922.

Mannino, D. M., Homa, D. M., Akinbami, L. J., Ford, E. S., \& Redd, S. C. (2002). Chronic obstructive pulmonary disease surveillance--United States, 1971-2000. Morbidity and Mortality Weekly Report Surveillance Summaries, 51(6), 1-16.

McFadden, E. R., Jr. (1990). Hypothesis: exercise-induced asthma as a vascular phenomenon. Lancet, 335, 880-883.

Mercken, E. M. et al. (2005). Rehabilitation Decreases Exercise-induced Oxidative Stress in Chronic Obstructive Pulmonary Disease. American Journal of Respiratory and Critical Care Medicine, 172, 994-1001.

Mikkelsen, R. L., Middelboe, T., Pisinger, C., \& Stage, K. B. (2004). Anxiety and depression in patients with chronic obstructive pulmonary disease (COPD). A review. Nordic Journal of Psychiatry, 58(1), 65-70.

Mosher, P. E., Nash, M. S., Perry, A. C., LaPerriere, A. R., \& Goldberg, R. B. (1998). Aerobic circuit exercise training: effect on adolescents with well-controlled insulindependent diabetes mellitus. Archives of Physical Medicine and Rehabilitation, 79, 652657.

Murray, C. J., \& Lopez, A. D. (1997). Alternative projections of mortality and disability by cause 1990-2020: Global Burden of Disease Study. Lancet, 349, 1498-1504. 
Physical Activity, Chronic Disease and Health

Nordfeldt, S., \& Ludvigsson, J. (2005). Fear and other disturbances of severe hypoglycaemia in children and adolescents with type 1 diabetes mellitus. Journal of Pediatric Endocrinology and Metabolism, 18, 83-91.

Oga, T., Nishimura, K., Tsukino, M., Sato, S., Hajiro, T., \& Mishima, M. (2005). Exercise capacity deterioration in patients with COPD: longitudinal evaluation over 5 years. Chest, $128,62-69$.

Petersen, K. H., \& McElhenney, T. R. (1965). Effects of a physical fitness program upon asthmatic boys. Pediatrics, 35, 295-299.

Pitta, F. et al. (2005). Characteristics of physical activities in daily life in chronic obstructive pulmonary disease. American Journal of Respiratory and Critical Care Medicine, 171(9), 972-977.

Porszasz, J. et al. (2005). Exercise training decreases ventilatory requirements and exerciseinduced hyperinflation at submaximal intensities in patients with COPD. Chest, 128, 20252034.

Prefaut, C., Varray, A., \& Vallet, G. (1995). Pathophysiological bases of exercise training in patients with chronic obstructive lung disease. European Respiratory Review, 5, 27-32.

Ram, F., Robinson, S., Black, P., Picot, J., \& Ram, F. S. (2005). Physical training for asthma. Cochrane Database Syst Rev(4), CD001116.

Ramazanoglu, Y. M., \& Kraemer, R. (1985). Cardiorespiratory response to physical conditioning in children with bronchial asthma. Pediatric Pulmonology, 1, 272-277.

Rees, J. (2005). ABC of asthma. Prevalence. British Medical Journal, 331(7514), 443-445.

Reid, M. B. (2001). COPD as a muscle disease. American Journal of Respiratory and Critical Care Medicine, 164, 1101-1102.

Scharloo, M., Kaptein, A. A., Weinman, J. A., Willems, L. N., \& Rooijmans, H. G. (2000). Physical and psychological correlates of functioning in patients with chronic obstructive pulmonary disease. J Asthma, 37, 17-29.

Serres, I., Gautier, V., Varray, A., \& Prefaut, C. (1998). Impaired skeletal muscle endurance related to physical inactivity and altered lung function in COPD patients. Chest, 113, 900905.

Serres, I., Varray, A., Vallet, G., Micallef, J. P., \& Prefaut, C. (1997). Improved skeletal muscle performance after individualized exercise training in patients with chronic obstructive pulmonary disease. Journal of Cardiopulmonary Rehabilitation, 17, 232-238. 
Physical Activity, Chronic Disease and Health

Shephard, R. J. (1982). Training and the respiratory system: therapy for asthma and other obstructive lung diseases? Annual Clinical Research, 14 Suppl 34, 86-96.

Shephard, R. J. (1984). Physical activity and child health. Sports Medicine, 1(3), 205-233.

Sheppard, D., \& Eschenbacher, W. (1984). Respiratory water loss as a stimulus to exerciseinduced bronchoconstriction. Journal of Allergy and Clinical Immunology, 7, 640-642.

Simon, M. et al. (2001). Limitation of lower limb VO(2) during cycling exercise in COPD patients. Journal of Applied Physiology, 90, 1013-1019.

Spruit, M. A. et al. (2003). Muscle force during an acute exacerbation in hospitalised patients with COPD and its relationship with CXCL8 and IGF-I. Thorax, 58, 752-756.

Stang, P., Lydick, E., Silberman, C., Kempel, A., \& Keating, E. T. (2000). The prevalence of COPD: using smoking rates to estimate disease frequency in the general population. Chest, $117(5$ Suppl 2), 354S-359S.

Szentagothai, K., Gyene, I., Szocska, M., \& Osvath, P. (1987). Physical exercise program for children with bronchial asthma. Pediatric Pulmonology, 3, 166-172.

Troosters, T., Casaburi, R., Gosselink, R., \& Decramer, M. (2005). Pulmonary rehabilitation in chronic obstructive pulmonary disease. American Journal of Respiratory and Critical Care Medicine, 172, 19-38.

Vallet, G. et al. (1997). Comparison of two training programmes in chronic airway limitation patients: standardized versus individualized protocols. European Respiratory Journal, 10, 114-122.

Vallet, G., Varray, A., Fontaine, J. L., \& Prefaut, C. (1994). Intérêt du réentraînement à l'effort individualisé, au niveau du seuil ventilatoire, au cours de la bronchopneumopathie chronique obstructive de sévérité modérée. Rev Mal Respir, 11, 493-501.

Varray, A., Mercier, J., Ramonatxo, M., \& Préfaut, C. (1989). Maximal exercise in asthmatic child: aerobic limitation and anaerobic compensation? Science \& Sports, 4, 199-207.

Varray, A., Mercier, J., Savy-Pacaux, A. M., \& Prefaut, C. (1993). Cardiac role in exercise limitation in asthmatic subjects with special reference to disease severity. European Respiratory Journal, 6, 1011-1017.

Varray, A., \& Prefaut, C. (1992). Importance of physical exercise training in asthmatics. Journal of Asthma, 29, 229-234.

Varray, A., \& Prefaut, C. (1995). Exercise training in patients with respiratory disease: procedures and results. European Respiratory Review, 5, 51-58. 
Physical Activity, Chronic Disease and Health

Varray, A. L., Mercier, J. G., \& Prefaut, C. G. (1995). Individualized training reduces excessive exercise hyperventilation in asthmatics. International Journal of Rehabilitation Research, 18, 297-312.

Varray, A. L., Mercier, J. G., Terral, C. M., \& Prefaut, C. G. (1991). Individualized aerobic and high intensity training for asthmatic children in an exercise readaptation program. Is training always helpful for better adaptation to exercise? Chest, 99, 579-586.

Vogiatzis, I., Williamson, A. F., Miles, J., \& Taylor, I. K. (1999). Physiological response to moderate exercise workloads in a pulmonary rehabilitation program in patients with varying degrees of airflow obstruction. Chest, 116, 1200-1207.

Wagena, E. J., Arrindell, W. A., Wouters, E. F., \& van Schayck, C. P. (2005). Are patients with COPD psychologically distressed? European Respiratory Journal, 26, 242-248.

Wardell, C. P., \& Isbister, C. (2000). A swimming program for children with asthma. Does it improve their quality of life? Medical Journal of Australia, 173, 647-648.

Welsh, L., Kemp, J. G., \& Roberts, R. G. (2005). Effects of physical conditioning on children and adolescents with asthma. Sports Medicine, 35, 127-141.

Whittom, F. et al. (1998). Histochemical and morphological characteristics of the vastus lateralis muscle in patients with chronic obstructive pulmonary disease. Medicine and Science in Sports \& Exercise, 30, 1467-1474.

Wuyam, B. et al. (1992). Metabolism and aerobic capacity of skeletal muscle in chronic respiratory failure related to chronic obstructive pulmonary disease. European Respiratory Journal, 5, 157-162. 
Table 1

Example of paradox between chronic physical activity effects and short term fears during exercise

\begin{tabular}{|l|l|l|}
\hline \multicolumn{1}{|c|}{ Disease } & \multicolumn{1}{|c|}{ Chronic effects of physical activity } & $\begin{array}{c}\text { Fear linked with physical } \\
\text { activity }\end{array}$ \\
\hline Asthma & $\begin{array}{l}\text { Improved exercise-induced } \\
\text { bronchodilation (Haas et al., 1987; Haas et } \\
\text { al., 1985) } \\
\text { Decreased risk of exercise-induced } \\
\text { bronchospasm by less exercise-induced } \\
\text { hyperventilation (Varray et al., 1995) }\end{array}$ & $\begin{array}{l}\text { Exercise-induced } \\
\text { bronchospasm attack }\end{array}$ \\
\hline COPD & $\begin{array}{l}\text { Decreased exercise hyperventilation for a } \\
\text { given work load (Vallet } \text { et al., 1997) } \\
\text { Decreased dyspnea with sharp quality of } \\
\text { life improvement (Lacasse } \text { et al., 1996) }\end{array}$ & Dyspnea worsening \\
\hline $\begin{array}{l}\text { Type I diabetes } \\
\text { mellitus }\end{array}$ & $\begin{array}{l}\text { Better metabolic control, less } \\
\text { hyperglycemia, increased glucose } \\
\text { tolerance (Bak et al., 1989; Mosher } \text { et al., } \\
\text { 1998) }\end{array}$ & $\begin{array}{l}\text { Problem of hypo- or } \\
\text { hyperglycemia during } \\
\text { exercise (Nordfeldt \& } \\
\text { Ludvigsson, 2005) }\end{array}$ \\
\hline
\end{tabular}


Figure 1. The vicious circle of hypoactivity illustrating how a chronic disease state can lead to functional deterioration [from Bar-Or (1985)]. Today, evidence indicates that functional deterioration has a major impact on symptoms of the chronic disease state.

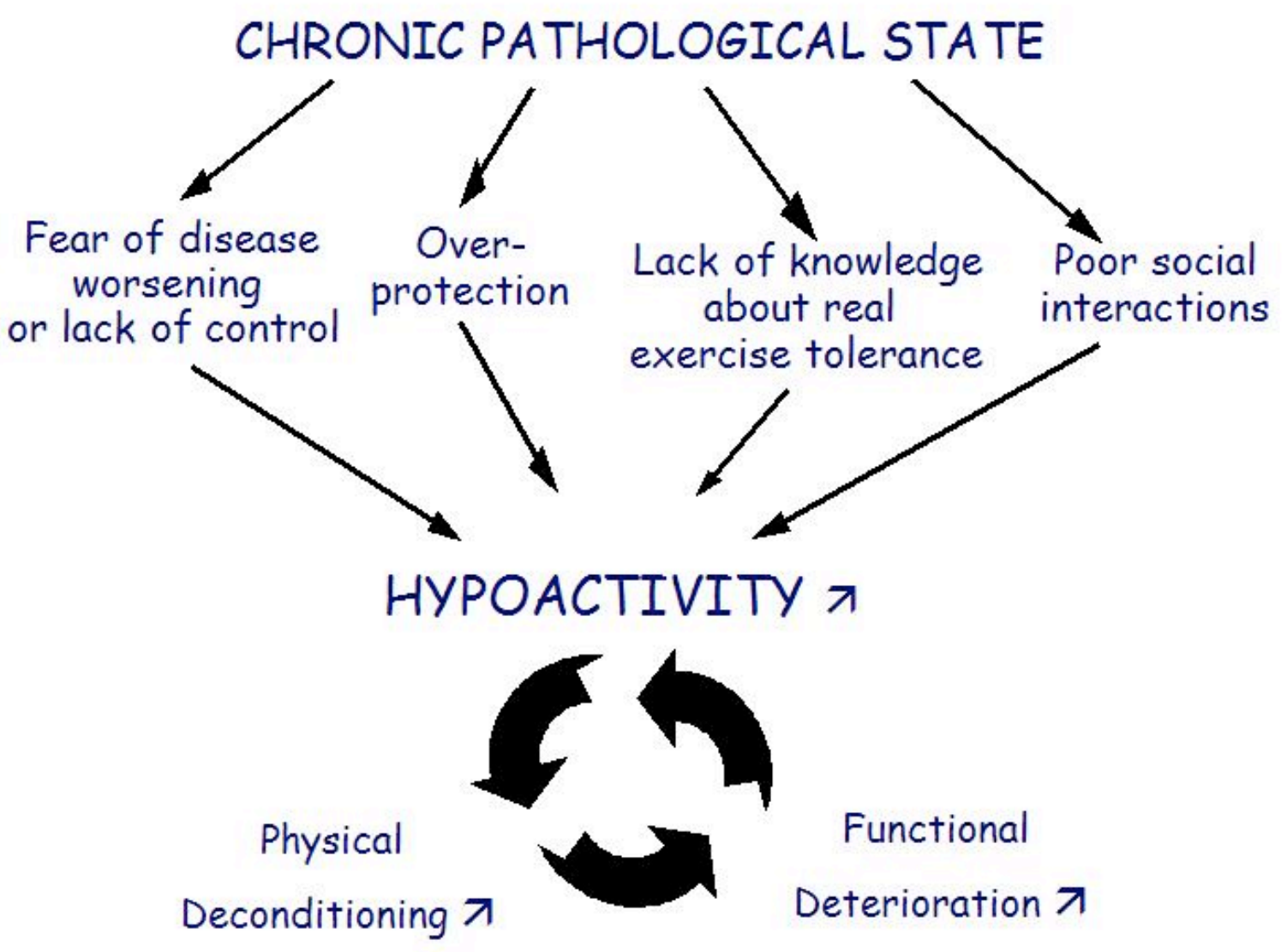


Figure 2. Dyspnea spiral leading to dyspnea worsening, irrespective of the progression of disease severity.

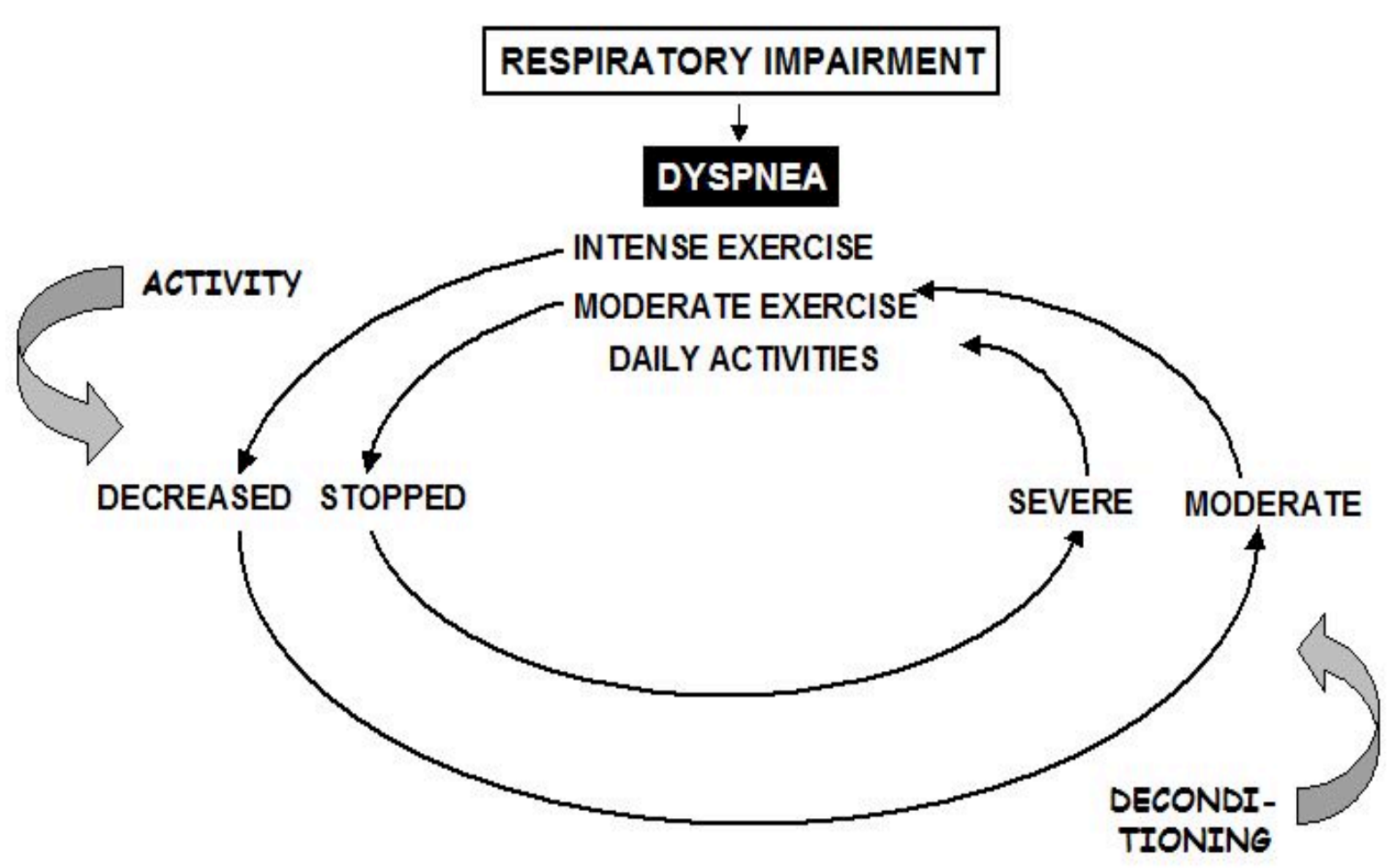


Figure 3. Ventilatory kinetics [ventilation and respiratory equivalent for oxygen ( $\left.\dot{\mathrm{V} E} / \dot{\mathrm{V}}_{2}\right)$ ] during incremental exercise prior to and after ventilatory threshold (VTh) appearance.

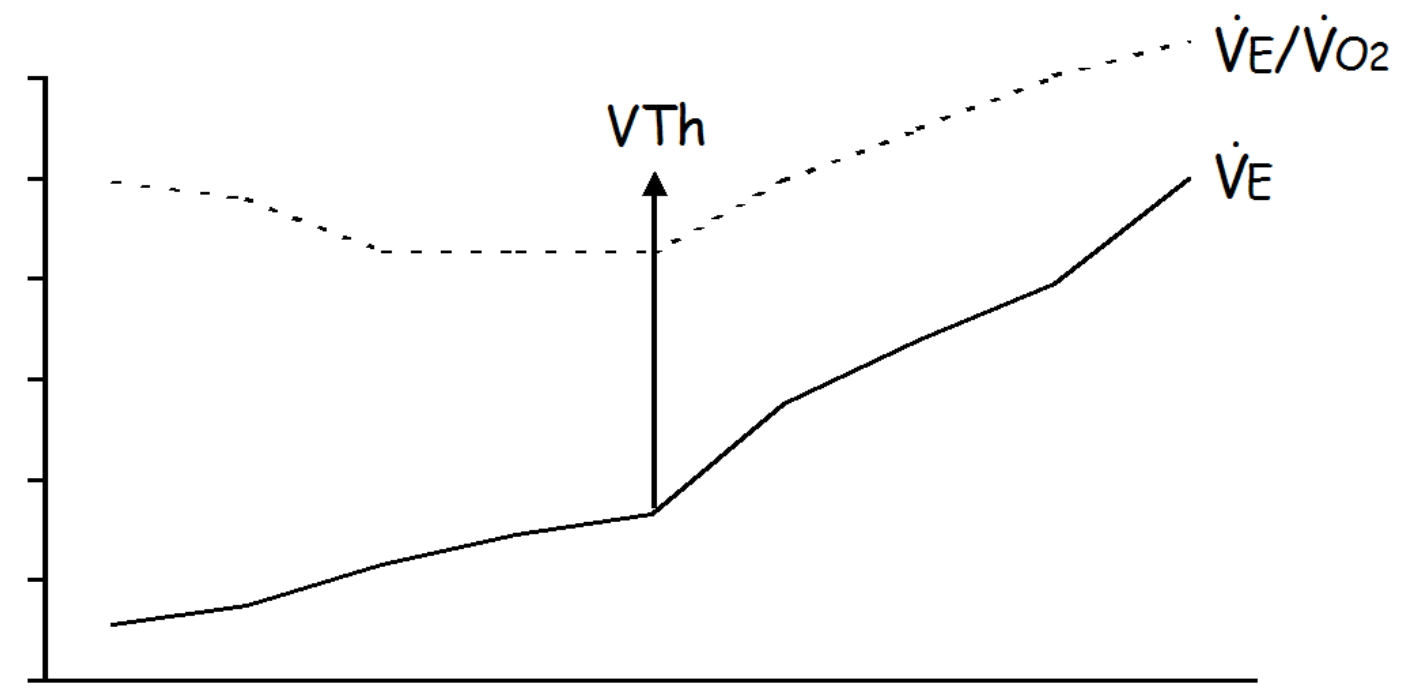

Workload $(W)$ 
Physical Activity, Chronic Disease and Health

Figure 4. Changes in M-wave amplitudes according to the level of activity and after individualized training in COPD. Data taken from Gosselin and co-workers (Gosselin, Lambert et al., 2003; Gosselin, Matecki et al., 2003). After training, muscle excitability can be maintained throughout exercise and recovery, as in healthy subjects.

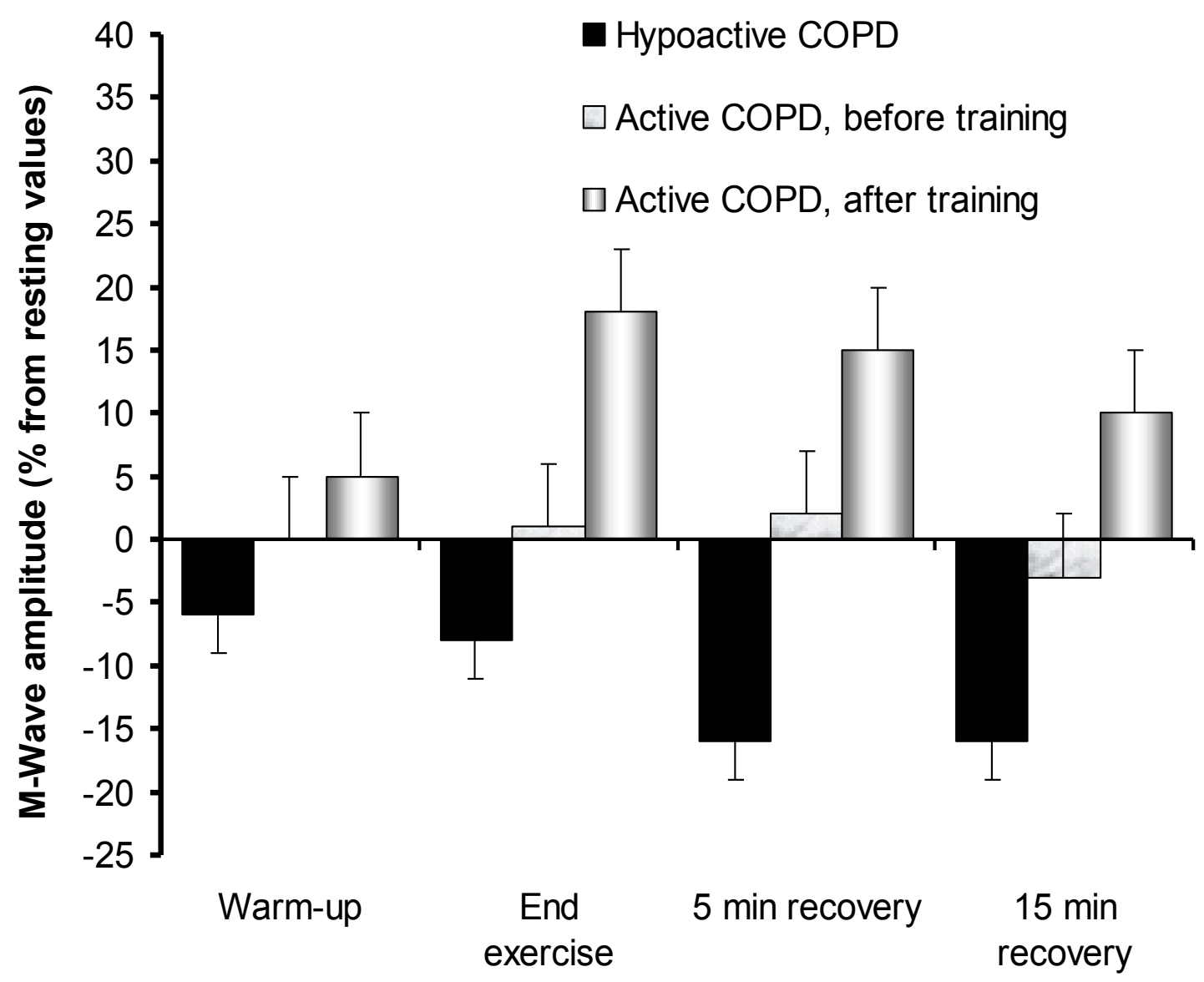


Figure 5. Differences in training effects on ventilation and index of anaerobic metabolism involvement for a given exercise intensity. In the group trained at $50 \%$ of heart rate reserve, training induced no effects (Vallet et al., 1997).

- Standardized training o Individualized training

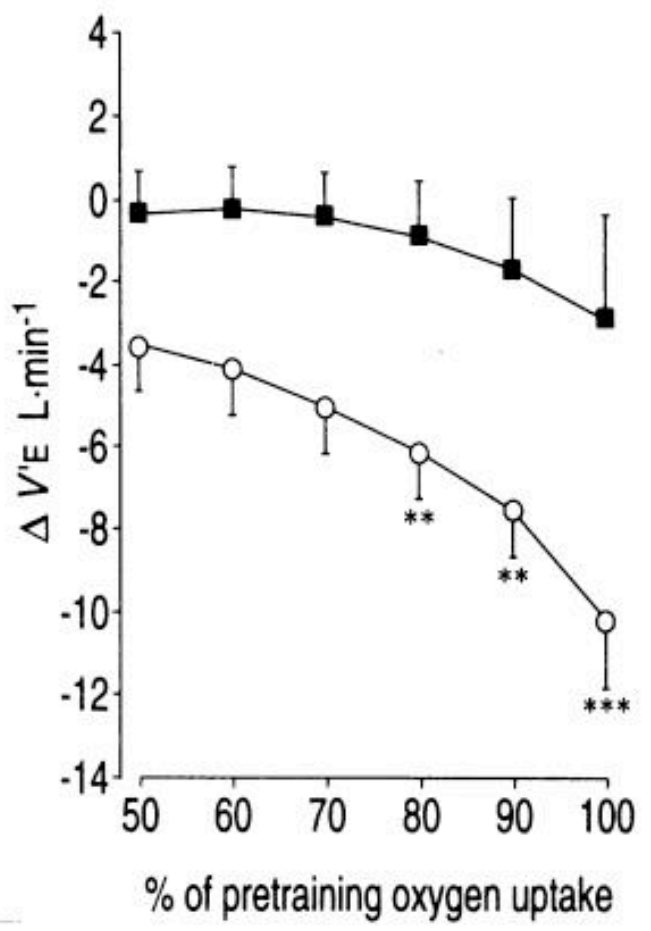

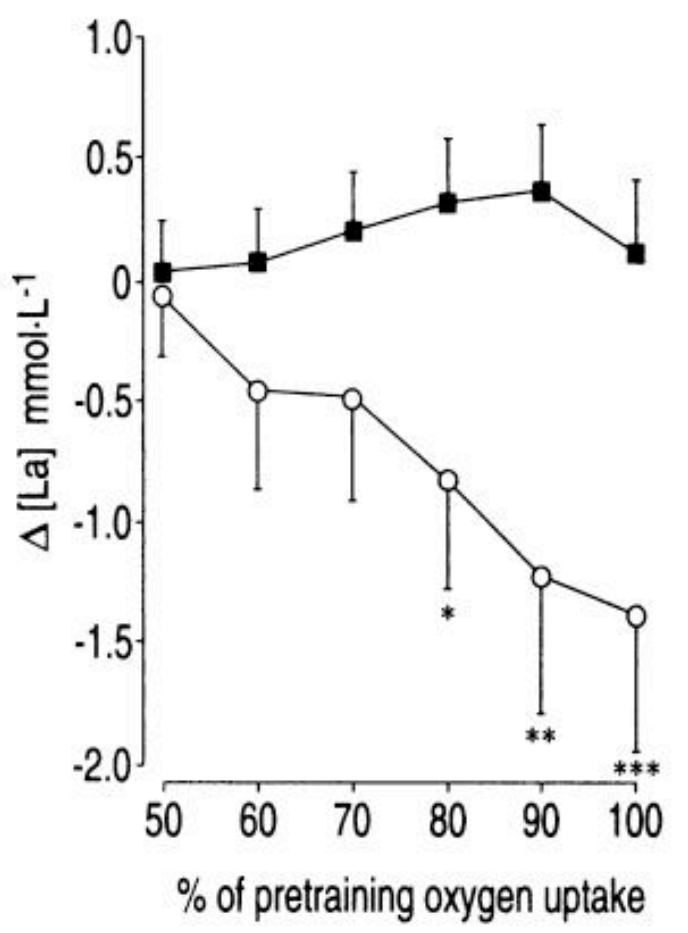

